\title{
EVALUATION OF THE AGDISP GROUND BOOM SPRAY DRIFT MODEL
}

\author{
S.J.R. WOODWARD ${ }^{1}$, R.J. CONNELL ${ }^{2}$, J.A. ZABKIEWICZ ${ }^{3}$, \\ K.D. STEELE ${ }^{3}$ and J.P. PRAAT ${ }^{1}$ \\ ${ }^{1}$ Lincoln Ventures Limited, Private Bag 3062, Hamilton, New Zealand \\ ${ }^{2}$ Lincoln Ventures Limited, PO Box 133, Lincoln, New Zealand \\ ${ }^{3}$ Plant Protection Chemistry ${ }_{N Z}, P O$ Box 6282, Rotorua, New Zealand
}

Corresponding author: connellr@lvl.co.nz

\begin{abstract}
AGDISP is a well-established spray drift model that has been validated for aerial spraying of forests. Recently a prototypical ground boom option has been added to AGDISP. This was evaluated in the current study by collecting data from spray trials over a grass sward using a ground boom sprayer and representative application parameters. Spray solutions were made up of water, sticker adjuvant and a metal cation, which was changed for each spray application. Deposition from spray drift was measured by analyses of the cation deposits on artificial targets (plastic tapes) placed on the grass surface. Measured deposition was compared with profiles calculated using AGDISP. AGDISP overpredicted deposition from spray drift by a factor of 3.5-100 outside the spray block. Possible reasons for these discrepancies are given. Options are to improve measured deposition and the algorithms for the deposition on the downwind swath of the spray block and evaporation of droplets.

Keywords: AGDISP evaluation, ground sprayer, spray drift, deposition profiles, metal cations.
\end{abstract}

\section{INTRODUCTION}

AGDISP is a well-established spray drift prediction software tool based on Lagrangian particle tracking theory (Bilanin et al. 1989). AGDISP simulates the release of spray droplets into a turbulent wind field above a crop canopy, and calculates their transport, dispersal, evaporation and final deposition onto crop and ground surfaces. AGDISP was originally developed for the USDA Forest Service for use in predicting drift from aerial spraying of forests and has achieved considerable accuracy in that application (Teske et al. 2003a).

Recently a prototypical ground boom spraying option was added to AGDISP (Teske et al. 2001), including nozzle orientation, pressure, exit velocity and air entrainment. However, limited validation studies on the ground boom option have highlighted discrepancies between drift predictions and field measurements, indicating that further development of this theory is required (Teske et al. 2001, 2004). This paper reports the results of comparing predictions made with the AGDISP ground application model (AGDISP 2003) with measurements made in a field trial as described in Zabkiewicz et al. (2008).

\section{MATERIALS AND METHODS}

Data were collected from spray trials over a grass sward using a ground boom sprayer and representative application parameters (Zabkiewicz et al. 2008). Spray solutions were made up of water, sticker adjuvant and a metal cation salt, the latter being changed for each spray application. The spray boom was $5 \mathrm{~m}$ long, with 10 XR TeeJet ${ }^{\circledR} 11003$ or 11004 flat fan nozzles spaced at $0.5 \mathrm{~m}$ intervals (positioned from $-2.25 \mathrm{~m}$ to $+2.25 \mathrm{~m}$ 
from the centre of the boom). Drop size distribution for each nozzle and each solution was determined using a Malvern 2600 laser droplet analyser in still air conditions, and differences between solutions were found to be small (Zabkiewicz et al. 2008). Nozzle height was $0.5 \mathrm{~m}$ above the soil surface. Ground cover was $0.1 \mathrm{~m}$ high grass.

Four $5 \mathrm{~m}$ wide swaths, each $20 \mathrm{~m}$ long, were sprayed for each of the treatments reported here. Target application rate was 200 litres/ha, delivered at a ground speed of $7 \mathrm{~km} / \mathrm{h}$. Deposition from spray drift was measured by analyses of cation salt deposits on three adjacent artificial targets (plastic tapes, approximately $10 \mathrm{~cm} \times 100 \mathrm{~cm}$; for percentage recovery, see Zabkiewicz et al. (2008)) placed on the grass surface within the spray area and at $0.5,1.5,3.0,5.0,10,15$ and $20 \mathrm{~m}$ downwind from the edge of the last swath. Spray application was with the two nozzles used alternatively to provide two replicates for each treatment combination.

Measured deposits were compared with profiles predicted using the AGDISP ground boom option. AGDISP parameters were set at $0.001 \mathrm{~m}, 0.01 \mathrm{~m}$ and $0.07 \mathrm{~m}$ respectively for surface roughness, canopy roughness and canopy displacement. Atmospheric stability was set to Day, Weak. AGDISP was run for a range of possible changes in wind speed and wind direction and also for changes in humidity. Other spray composition and atmospheric parameters are given in Table 1.

\section{RESULTS AND DISCUSSION}

AgDisp has been tested using over 48 field data sets (Teske et al. 2004) and the results showed a range of modelled to actual depositions that varied by \pm two orders of magnitude. The results presented here are within this envelope, so this analysis has concentrated on the operational parameters to identify factors to explain the differences between our data sets and the modelling results.

AGDISP was used to predict deposition from spray drift from four treatments (out of a total of eight in the trial) to compare with field measurements of cation deposition as a percentage of applied. Results of calculated and actual deposition for Treatments 2 and 6 (with XR Teejet 11004 nozzles) and Treatments 4 and 8 (with XR Teejet 11003 nozzles) are shown in Figures 1a and $1 \mathrm{~b}$.
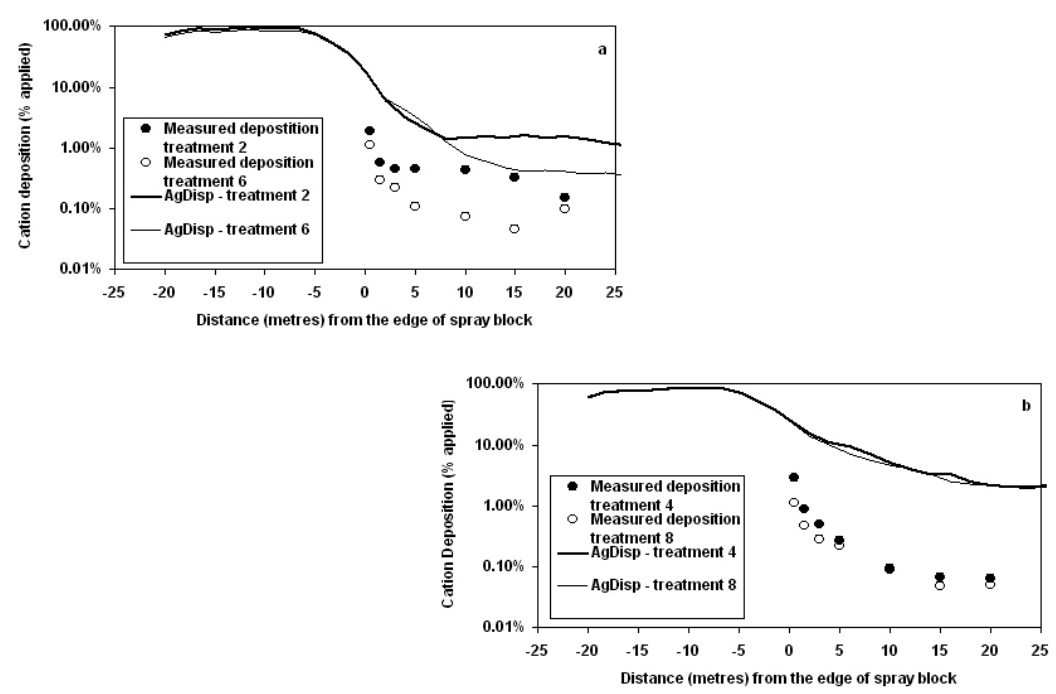

FIGURE 1: AGDISP drift predictions of cation deposition (\% applied) for (a) treatments 2 and 6 using the XR TeeJet ${ }^{\circledR} 11004$ nozzles and (b) treatments 4 and 8 using the XR TeeJet ${ }^{\circledR} 11003$ nozzles. 
TABLE 1: Operational and environmental conditions.

\begin{tabular}{|c|c|c|c|c|c|}
\hline Treatment number & & 2 & 4 & 6 & 8 \\
\hline $\begin{array}{l}\text { Nozzle (XR } \\
\text { TeeJet }^{\circledR} \text { series }^{\text {Non }}\end{array}$ & & 11004 & 11003 & 11004 & 11003 \\
\hline Boom pressure & bar & 1.5 & 3 & 1.5 & 3 \\
\hline $\begin{array}{l}\text { Volume median } \\
\text { diameter }^{1}\end{array}$ & $\mu \mathrm{m}$ & 230 & 164 & 230 & 164 \\
\hline $\begin{array}{l}\text { Relative span } \\
\text { of drop size } \\
\text { distribution }{ }^{1}\end{array}$ & & 1.57 & 1.57 & 1.57 & 1.57 \\
\hline Salt used & & $\begin{array}{c}\mathrm{Co}\left(\mathrm{NO}_{3}\right)_{2} \\
6 \mathrm{H}_{2} \mathrm{O}\end{array}$ & $\mathrm{KCl}$ & $\mathrm{MnCl}_{2}$ & $\mathrm{MgCl}_{2}$ \\
\hline $\begin{array}{l}\text { Salt added per } 50 \\
\text { litres water }\end{array}$ & $\mathrm{g}$ & 20 & 2000 & 20 & 1255 \\
\hline $\begin{array}{l}\text { Nominal cation } \\
\text { application rate }\end{array}$ & $\mu \mathrm{g} / \mathrm{cm}^{2}$ & 0.162 & 42.0 & 0.222 & 12.8 \\
\hline $\begin{array}{l}\text { Measured cation } \\
\text { application rate }\end{array}$ & $\mu \mathrm{g} / \mathrm{cm}^{2}$ & 0.133 & 28.6 & 0.168 & 9.63 \\
\hline $\begin{array}{l}\text { Active (salt) } \\
\text { volume fraction }\end{array}$ & & 0.000081 & 0.0210 & 0.000111 & 0.00641 \\
\hline $\begin{array}{l}\text { Non-volatile } \\
\text { volume fraction }\end{array}$ & & 0.0014 & 0.041 & 0.0014 & 0.0261 \\
\hline $\begin{array}{l}\text { Average wind } \\
\text { speed (and range) }\end{array}$ & $\mathrm{m} / \mathrm{s}$ & $\begin{array}{c}1.58 \\
(1.05-1.95)\end{array}$ & $\begin{array}{c}3.3 \\
(2.36-3.92)\end{array}$ & $\begin{array}{c}1.65 \\
(1.12-2.20)\end{array}$ & $\begin{array}{c}2.75 \\
(2.13-3.59)\end{array}$ \\
\hline $\begin{array}{l}\text { Average wind } \\
\text { direction }^{4}\end{array}$ & o & -91 & -104 & -114 & -106 \\
\hline $\begin{array}{l}\text { Average } \\
\text { temperature }\end{array}$ & ${ }^{\circ} \mathrm{C}$ & 13.1 & 12.1 & 11.8 & 11.5 \\
\hline Average humidity & $\%$ & 65 & 81 & 78 & 81 \\
\hline
\end{tabular}

${ }^{1}$ In AGDISP, drop size distribution was set using the Parametric option with these parameters, and then Interpolated to give finer definition at the smaller drop sizes. Failure to Interpolate the Parametric distribution resulted in highly variable predictions of drift.

${ }^{2} 50 \mathrm{ml}$ liquid adjuvant (Bond Xtra) was also added per 50 litres of water.

${ }^{3}$ In calculating the volume fractions, it was assumed that the specific gravities of the salt and adjuvant were 1 , since AGDISP does not allow these to be specified separately. This assumption had negligible impact on the results.

${ }^{4} \mathrm{~A}$ wind direction of -90 is at right angles to the spray line.

AGDISP correctly calculated the deposition of cation within the spray block itself (i.e. the region to the left of $0 \mathrm{~m}$ ), except that AGDISP predicted a decline in deposition in the last $7 \mathrm{~m}$ of the spray block. This is an issue arising from using the aerial model for the ground boom model where the nozzles are much closer to the ground.

Downwind of the spray block AGDISP over-predicted deposition by between 3.5 and 100 times the measured values. A sensitivity analysis was undertaken within known variations in wind speed and changes in wind direction for treatment 2 to test the effects these would have on the results. Varying the wind speed within the ranges recorded for treatment 2 did change the deposition profiles of AGDISP (by $-25 \%$ to $+50 \%$ ), but it still overestimated by 3.5 (from the original 10-fold) times at $10-20 \mathrm{~m}$ downwind. Using 
a maximum change in wind direction of \pm 20 degrees, AGDISP showed a decrease in deposition between 5 and $10 \mathrm{~m}$ for treatment 2 from about 10 times to about 2.7 times the measured deposition.

AGDISP also predicted an increase in deposition when evaporation was excluded from the calculation (or increasing the humidity to $100 \%$ ). This is expected, as increasing the humidity increases deposition near the spray block (Teske et al.2002). Running AGDISP simulations for treatments 4 and 8 with humidity at $90 \%$ (approximately midway between actual and $100 \%$ humidity) showed increased calculated deposition with increasing humidity, moving values further from experimental values. Similar simulations for treatments 2 and 6 did not show increased deposition with increased humidity. The runs with a humidity midway between actual and $100 \%$ humidity showed a marked decrease in calculated deposition that was within $+40 \%$ of actual results for treatment 2 at $10-20$ m downwind and within $+100 \%$ for treatment 6 . The reason for this was that the mass of non-volatiles applied in treatments 2 and 6 were over an order of magnitude less than treatments 4 and 8 and below the normal limits of AGDISP. This indicates that the evaporation algorithm in AGDISP (Teske et al. 2003b) needs improvement, and work is in progress (Teske \& Thistle 2008).

As in previous validation studies, considerable differences were observed between measured and calculated profiles of downwind deposition, with AGDISP overestimating off-target deposition by a factor of 3.5 to 100. The reasons for this are unclear, but Teske et al. (2004) point out that AGDISP, being originally an aerial spraying model, does not consider many of the factors that could be important for ground application.

Furthermore measured drift was greater when coarser nozzles were used (XR TeeJet ${ }^{\circledR}$ 11004) compared with finer nozzles (XR TeeJet ${ }^{\circledR}$ 11003). A possible explanation for this is that the higher pressure used with the finer nozzles resulted in spray being driven into the canopy before drift could occur. Teske et al. (2004) indicated this aspect of AGDISP needed further evaluation. Another explanation is that the spray was not collected efficiently within the measured distance. These are areas where further work is needed.

\section{CONCLUSIONS}

Despite adjustment to fit several data sets (Teske et al. 2001, 2004), the ground boom option of AGDISP has never been presented as being anything more than a prototype, and has been found to perform poorly in several independent validation trials (Hewitt et al. 2002). This is backed up by the current study. Nevertheless, if the AGDISP ground boom model could be improved it would provide an excellent tool for predicting and mitigating drift from ground spraying operations. The results presented here indicate some of the directions where future ground boom model development efforts might be focused, that is, deposition at the downwind swath of the spray block and the evaporation algorithm.

\section{ACKNOWLEDGEMENTS}

This research was carried out as part of the Foundation for Research, Science and Technology "Biomarker Technology" programme (LVLX0304). We thank the USDA Forest Service for providing us with AGDISP (2003) to use in this project. D. Horgan, M. Geddes, A. Pathan and B. Moorhead assisted with the field trial. Lastly we would like to thank the reviewers, Brian Richardson and Alison Forster, for helpful comments on this paper. 


\section{REFERENCES}

AGDISP 2003. USDA Forest Service Spray Modeling Software, version 8.15, Harold W. Thistle, USDA Forest Service, 180 Canfield Street, Morgantown, WV 26505.

Bilanin AJ, Teske ME, Barry JW, Ekblad RB 1989.AGDISP: The aircraft spray dispersion model, code development and experimental validation. Transactions of the American Society of Agricultural Engineers 32(1): 327-334.

Hewitt AJ, Maber J, Praat JP 2002. Drift management using modeling and GIS systems. In: Zazueta FS, Xin J ed. Proceedings of the World Congress of Computers in Agriculture and Natural Resources, 13-15 March 2002, Iguaçu Falls, Brazil. Publication No. 701P0301, American Society of Agricultural Engineers, St Joseph, MI 49085. Pp. 290-296.

Teske ME, Valcore DL, Hewitt AJ 2001. An analytical ground sprayer model. Presented at 2001 American Society of Agricultural Engineers International Meeting, Sacramento, California, 30 July-1 August 2001.

Teske ME, Bird SL, Esterly DM, Curbishley TB, Ray WL, Perry SG 2002.AgDRIFT®: A model for estimating near-field spray drift from aerial applications. Environmental Toxicology and Chemistry 21(3): 659-671.

Teske ME, Thistle HW, Ice GG 2003a. Technical advances in modeling aerially applied sprays. Transactions of the American Society of Agricultural Engineers 46(4): 985-996.

Teske ME, Thistle HW, Hewitt AJ, Valcore DL 2003b. Droplet evaporation corrections for aerial spray drift modeling 1: Theoretical considerations. Atomization and Sprays 13: 243-250.

Teske ME, Birchfield NB, Bird SL 2004. Development and validation of a mechanistic ground sprayer model. Presented at 2004 American Society of Agricultural Engineers/Canadian Society of Agricultural Engineering International Meeting, Ottawa, Canada, 1-4 August 2004.

Teske ME, Thistle, HW 2008. A Model for Multi-Component Evaporation of Aerial Sprays. Presented at the American Society of Agricultural and Biological Engineers International Meeting, Providence, Rhode Island, 29 June-2 July 2008.

Zabkiewicz JA, Steele KD, Praat JP 2008. Determination of spray drift using multiple metal cations as tracers. New Zealand Plant Protection 61: 159-163. 